Introduction The field of ergonomics and the field of quality have a history as two separate disciplines. Both fields are relatively young and are largely of an applied nature. The dominating paradigms have undergone changes in recent years. On the other hand, Health and Safety has its own place, centred in the improvement of working conditions. At TAP PORTUGAL, these three domains are organised in such a way that the ergonomics interventions are embedded in the Occupational Health and Safety department, at UCS, the healthcare provider for all the TAP group companies. One of these companies is the maintenance unit, a MRO, TAP Maintenance and Engineering that plans each year, two Continuous Improvement Weeks and recently the ergonomist has been invited to collaborate.

Methods The ergonomist was invited to participate in three Continuous Improvement Weeks, part of a multidisciplinary team (4 elements) with workers and engineers. The projects were: 'Redesign of a Coffee Machines Test Bench'; 'Brake parts transportation cart' and 'Maintenance aircraft lighting'. The ergonomic analysis methodologies were applied as well as the tools of continuous improvement, requiring an effort of adaptation between the professional different points of view.

Results Both Quality and Ergonomics tools were applied and the teams produced recommendations regarding performance and health and safety concerns.

Discussion The introduction of an ergonomist in the team of continuous improvement improves the final result of the process since the importance of the human factor is determinant for the success of the projects. In order to participate in these teams the ergonomist needs to master the Quality analysis tools, to have the time to carry out the work activity analysis and to obtain information (especially KPI) of both ergonomics and health and safety domains.

\section{WORKING CONDITIONS IN GERMAN HOSPITALS- PREVENTION FOR YOUNG PHYSICIANS AND NURSING STAFF IN GERMANY}

Peter Koch, Albert Nienhaus. University Medical Center Hamburg Eppendorf, Hamburg, Germany

\subsection{6/oemed-2018-ICOHabstracts.446}

Background The implementation of the Diagnose Related Groups-System in Germany has led to substantial work intensification over the years. Due to these structural changes a high dissatisfaction with work and early exit from work especially for nursing staff has been observed in studies. Also physicians working in hospitals complain about their working conditions characterised by not documented overtime, personnel shortage, missing breaks and a perceived lower care quality. With respect to these working conditions, the demographic development of patients and health care workers, young health care workers today are the future potential of the capacity of German hospitals. The following research investigates the working conditions of young physicians and nurses in a joint context. The aim of this study is to detect specific needs for improvement with respect to the collaboration of the two job groups.
Methods The statutory accident insurance of health care workers in Germany (BGW) has the statutory obligation to prevent work- related diseases. In collaboration with two unions and several medical and nursing societies the BGW is performing a large representative survey in September 2017. The study population are young physicians and nurses ( $\leq 35$ years) working in German hospitals. Access to the field will be attained by the different databases of the union and society members. A randomised sample of 8000 young health care workers will get access to the web-based survey via email. The questionnaire will assess different work-related aspects with the Copenhagen Psychosocial Questionnaire (COPSQ). Other psychosocial factors will be assessed with the Effort-RewardImbalance-Questionnaire (ERI). Especially aspects of collaboration of the two job groups and specific needs for improvement that are asked in the questionnaire, will give essential information to build up new strategies to enhance work satisfaction of young health care workers.

\section{DEVELOPMENT OF OCCUPATIONAL HEALTH SERVICES PRACTICES STANDARDS IN ACCREDITING PRIMARY CARE UNITS IN THAILAND}

O Untimanon*, K Boonmeephong, A Promrat, T Saipang, K Sukanun. Bureau of Occupational and Environmental Diseases, Department of Disease Control, Ministry of Public Health, Thailand

\subsection{6/oemed-2018-ICOHabstracts.447}

Introduction A total of 9770 primary care units (PCUs) in Thailand have provided many health care services, such as the improvement of nutrition of young children, immunisation, investigations of communicable diseases and non- communicable diseases. Integration of occupational health services (OHS) in the PCUs is very important because high risk workers who work in the communities can access such services easily. Implementation strategy can start with quality control program that integrating with holistic healthcare delivered by PCUs therefore the OHS practices standards were developed to be a guideline for PCUs to carry out OHS interventions.

Methods The OHS practices standards were developed using Delphi technique. Thirty Delphi panellists from related agencies were asked to answer the 3 rounds of questionnaire. Consensuses were formed and the actual outcomes could be presented among the panellists' response. Such standards were summarised and figured. The criteria were developed following the items of such standards. Draft standards and criteria were used to evaluate the pilot PCUs and they were revised to be more clearly following the suggestion to suit the real situation.

Results Such standards were divided into four components including:

- organisational set up, human resources, plans, evaluation and occupational health network collaboration,

- OHS for health worker of PCUs,

- pro-active occupational health services for community workers,

- in-house occupational health services and

- integration of environmental health services. 
Assessment criteria were classified into 4 levels including starting level, good level, very good level and excellent level PCUs depending on the ability of PCUs practices.

Conclusion PCUs' staff could provide the OHS following such standard which address not only health services for community workers, but also for health workers (PCUs staff) and vulnerable populations who affect from environmental pollutions in the community (if have).

\section{FINDING AT-RISK, LOW WAGE WORKERS IN COMMUNITY HEALTH CENTRES IN THE US}

Linda Forst*, Liza Topete, Joseph Zanoni, Lee Friedman. University of Illinois at Chicago School of Public Health, Chicago, Illinois, USA

\subsection{6/oemed-2018-ICOHabstracts.448}

Introduction The 'working poor' bear an inequitable burden of work-related injuries, illnesses, and fatalities. They often obtain healthcare in community health centres (CHCs) and do not report work-relatedness. The aim was to determine whether the $\mathrm{CHCs}$ are a high yield venue for reaching low wage workers and to examine low-wage workers' experience with Workers' Compensation (WC).

Methods A mixed methods survey was conducted in rural and urban CHCs.

Results 50 interviews among largely Latino and African-American workers from 11 different sectors and 41 different job titles, most of them associated with low wages, showed: $55 \%$ had experience with a work-related; all knew the employer was responsible for health care. Most respondents did not access their full rights. The major reporting barriers were fear of job loss, fear of deportation, and personal stoicism. Knowing one's rights and finding an advocate were noted facilitators of reporting.

Discussion Lack of reporting circumvents the use of WC, depriving these patients of optimal healthcare and limiting access to medication, rehabilitation, disability compensation and wage replacement. Furthermore, it shifts the burden of fee reimbursement to CHCs, federal programs, and the worker-patients. Fear of job loss and deportation of adds to the list of rights infringement and root causes of health inequities. Increasing knowledge of labour laws and health and safety protections should improve health outcomes. Lowwage, at-risk, and formerly injured workers were easy to find in a CHC, suggesting that this as a venue for training of workers and of primary care providers. Policy initiatives to protect these workers are critical.

\section{EFFECTIVENESS EVALUATION IN OCCUPATIONAL HEALTH}

Stefano Mattioli*. Department of Medical and Surgical Sciences, University of Bologna, Italy

\subsection{6/oemed-2018-ICOHabstracts.449}

Aim of special session To provide elements useful to evaluate preventive interventions in occupational health and to disseminate its results

Presenters: ${ }^{1}$ Stefano Mattioli, ${ }^{1}$ Stefania Curti, ${ }^{2}$ Jani H Ruotsalainen, ${ }^{3}$ Henk $\mathrm{F}$ van der Molen

${ }^{1}$ Department of Medical and Surgical Sciences, University of Bologna, Italy
${ }^{2}$ Cochrane Work, Finnish Institute of Occupational Health, Kuopio, Finland

${ }^{3}$ Academic Medical Centre, University of Amsterdam, Department: Coronel Institute of Occupational Health, Amsterdam Public Health research institute, Amsterdam, The Netherlands

\section{2a PREVENTIVE INTERVENTIONS: TO EVALUATE OR NOT TO EVALUATE?}

S Mattioli. Department of Medical and Surgical Sciences, University of Bologna, Italy

10.1136/oemed-2018-ICOHabstracts.450

The production of studies regarding the evaluation of the effectiveness of preventive interventions is still modest, especially in comparison with the production of effectiveness studies in the clinical field. This can be at least partly due to the real difficulty to evaluate the effects of preventive actions on injuries at work and on occupational diseases, which can be affected by many other causal factors, including regulatory actions, periods of economic and employment crisis, technological innovations, changes in the distribution of risk factors in the population.

Such complexity must be carefully considered when the researcher approaches the effectiveness evaluation in the occupational health field and, to do so, the evaluation of effectiveness should be planned before to start with the intervention.

Three elements have to be clearly defined:

1. the objective of the assessment;

2. the intervention that the researcher wants to evaluate; and

3. the outcome to be measured as effect of the intervention itself.

At the same time, it should be ensured whether the considered preventive intervention has already been studied. This could be performed searching the literature, in order to find the information relevant to the problem that needs to be addressed.

Finally, before promoting the intervention - on the basis of technical knowledge and availability of the tools, considering also economical and time concerns - it is necessary to choose the type of study design that is more appropriate and feasible to assess the effectiveness of the intervention: it has to be considered the growing evidence coming from studies like case-report, cross-sectional, before-after, controlled before-after, interrupted time series, case-control, cohort and randomised (individually or by cluster) controlled trials.

\section{2b HOW TO EXECUTE AN EFFECTIVE SEARCH ON PUBMED BEFORE CARRYING OUT A PREVENTIVE INTERVENTION}

\section{S Curti. Department of Medical and Surgical Sciences, University of Bologna, Italy}

\subsection{6/oemed-2018-ICOHabstracts.451}

Well-defined search strategies can provide efficient and effective tools to help addressing specific research questions in the field of evidence-based prevention in occupational health. The planning of a preventive intervention is a fundamental process for the evaluation of the effectiveness of the intervention. The first step is to explore the scientific literature to retrieve all 